\title{
Ageing in urban environments: Developing 'age-friendly' cities
}

\section{T I NE B UFFEL}

Free University of Brussels, National Fund for

Scientific Research, Belgium

\section{CHR I S PHILL I P S O N}

Keele University

\section{THOMAS SCHARF}

National University of Ireland, Galway

\begin{abstract}
Developing environments responsive to the aspirations and needs of older people has become a major concern for social and public policy. This article aims to provide a critical perspective on what has been termed 'age-friendly cities' by shifting the focus from questions such as 'What is an ideal city for older people?' to the question of 'How agefriendly are cities?' This approach, it is argued, might be more suited to deal with the complexities of cities as sites of interlocking and conflicting commercial, social, and political interests. This theme is developed by examining: first, the main factors driving the age-friendly debate; second, constraints and opportunities for older people living in urban environments; third, options for a critical social policy; and, fourth, examples of involving older people in the development of age-friendly environments. The article concludes with a brief summary of current tensions and contradictions in the age-friendly debate.
\end{abstract}




\section{Key words \\ older people, urban communities, urban development}

\section{Introduction}

Developing 'age-friendly' communities has become a significant issue for social policy, embracing questions ranging across urban as well as rural environments. A number of factors have stimulated discussion around this topic, these including: first, the global impact of demographic change, with a wide range of housing and community needs emerging among those aged 50 and over (Biggs et al., 2000); second, the policy goal of supporting people in their own homes for as long as possible - the idea of 'ageing in place' (Lui et al., 2009); third, awareness of the impact of urban change on the lives of older people, notably in areas experiencing social and economic deprivation (Scharf et al., 2002); and, fourth, debates about 'good' or 'optimal' places to age, these stimulated by the growth of retirement communities serving the needs of particular groups of older people (Bernard et al., 2004; Evans, 2009).

The model of 'age-friendly cities' initiated by the World Health Organization (WHO) (2007a) reflects attempts to develop supportive urban communities for older citizens. These have been defined as encouraging 'active ageing by optimizing opportunities for health, participation and security in order to enhance quality of life as people age' (WHO, 2007a: 12). This goal should be seen in the context of the twin forces of population ageing and urbanization, both now identified as among the most significant social trends affecting life in the twenty-first century (Burdett and Sudjic, 2008). By 2030, two-thirds of the world's population will be residing in cities, with - for urban areas in high-income countries - at least one-quarter of their populations aged 60 and over (UN-Habitat, 2010). The global 'agefriendly' city perspective has been influential in raising awareness about the impact of population ageing, especially for the management and planning of urban environments. Against this, the value of this approach has yet to be properly assessed in the context of the complexities and contradictions that beset modern cities, especially those that arise from accelerated global social and economic change.

Given the above, the aim of this article is to provide a critical perspective on the 'age-friendly' movement, linking this to more general research and policy debates about the experience of ageing within urban environments. To address this area, the following questions will be explored:

- What have been the main factors driving the debate on creating agefriendly cities?

- What are the constraints and opportunities for older people living in urban environments? 
- What are the options for a critical social policy focused on older people in urban areas?

- What examples are available for involving older people in developing age-friendly environments?

\section{Developing age-friendly cities}

The issue of developing age-friendly communities arose from a number of policy initiatives launched by the WHO during the 1990s and early 2000s. A central theme running through these concerned the idea of 'active ageing', originally developed during the United Nations' Year of Older People in 1999 and further elaborated by the European Union (1999) and the WHO (2002). Within this context, the WHO (2002) stressed that the notion of 'active' refers to the idea that older people should be able to continue to participate in social, cultural, spiritual, economic and civic matters, i.e. not just the ability to participate in the labour market or to be physically active. Policies and programmes directed at achieving active ageing were considered to require a wide range of interventions, including actions at the level of the social and physical environment.

This idea was taken further in 2006, when the WHO launched the 'Global Age-friendly Cities' project. In 33 cities around the world, focus groups with older people, caregivers, and service providers were formed in order to identify those factors that make urban environments 'age-friendly'. A resulting checklist of action points addressed aspects of service provision (e.g. health services, transportation), as well as dimensions of the built environment (e.g. housing, outdoor spaces and buildings), and social aspects (e.g. civic and social participation) (WHO, 2007b). This work concluded that progress in developing these action points should make cities 'friendly for all ages' and not just 'elder-friendly': 'it should be normal in an age-friendly city for the natural and built environment to anticipate users with different capacities instead of designing for the mythical “average” (i.e. young) person' (WHO, 2007a: 72). Building on this work, in 2010 the WHO launched the 'Global Network of Age-friendly Cities', in an attempt to encourage implementation of policy recommendations from the 2006 project. The WHO network includes 47 individual cities (including Manchester in the UK) with many others involved in national programmes.

The possibility of creating age-friendly cities may be linked with models of urban development produced during the 1990s and early 2000s, notably ideas around 'sustainable' and 'harmonious cities'. The former raised questions about managing urban growth in a manner able to meet the needs of future as well as current generations (Satterthwaite, 1999). The latter emphasized values such as 'tolerance, fairness, social justice and good governance', these regarded as essential in achieving sustainable development in urban planning 
(UN-Habitat, 2008: x). Such themes were also influential in the elaboration of ideas associated with 'lifetime homes' and 'lifetime neighbourhoods', which emerged in the UK with acceptance of the need for policies to support population ageing at a community level (Department for Communities and Local Government, 2008). An additional influence was recognition of the development in many localities of what came to be termed 'naturally occurring retirement communities' (NORCs), i.e. neighbourhoods that, with the migration of younger people, effectively evolved into communities of older people. The key issue behind the 'lifetime' concept was an understanding that effective support for older people within neighbourhoods would require a range of interventions linking different parts of the urban system - from housing and the design of streets to transportation and improved accessibility to shops and services (Atlanta Regional Commission, 2009).

Lui and colleagues (2009), however, suggest that there are different approaches to how favourable environments for older citizens might be sustained, with models ranging from emphasis on the physical/social environment on the one hand, and from top-down to bottom-up governance on the other. Some models focus more on physical infrastructure and design (Atlanta Regional Commission, 2009), while others (e.g. the UK model of Lifetime Neighbourhoods) pay more attention towards social aspects of the environment, i.e. formal and informal relationships, participation and inclusion (Department for Communities and Local Government, 2008). With regard to governance processes, some approaches concentrate on empowering and involving older people as the main actors in enhancing neighbourhoods, for example the Calgary Elder Friendly Communities programme in Canada (Austin et al., 2005). In contrast, top-down approaches, such as the WHO's model of Global Age-Friendly Cities (2007a), primarily involve policy-makers and focus groups of older people in assessing environments against established criteria or checklists (Lui et al., 2009).

Notwithstanding different approaches, a common link lies in the way most appear to rest on a model of the 'ideal' city achieved through appropriate policy and service interventions. ${ }^{1}$ The global age-friendly perspective might be seen as the clearest illustration. A checklist of 88 'core age-friendly features', applying to 'less developed as well as more developed cities', has been produced in order to provide 'a universal standard for an age-friendly city' (WHO, 2007a: 11). Items include requirements that:

- 'Public areas are clean and pleasant';

- 'Sufficient, affordable housing is available in areas that are safe and close to services and the rest of the community';

- 'Older people who are less well-off have good access to public, voluntary and private services'; and

- 'Public and commercial services provide friendly, person-to-person service on request.' 
However, against what might be termed the 'idealistic model', a focus on the material conditions of city life may be a better starting point for understanding pressures on the lives of older people. With this approach, the focus shifts from questions such as: 'What is an ideal city for older people?' to the question of 'What are the actual opportunities and constraints in cities for maintaining quality of life as people age?' Or, alternatively, from: 'What is an age-friendly city?' to 'How age-friendly are cities?' This perspective, it will be argued, might be more suited to deal with the complexities of cities as sites of interlocking and conflicting commercial, social, and political interests.

The above questions might be judged to be of particular importance in the context of the global forces influencing urban neighbourhoods, with movements of capital producing uneven development within as well as between cities (Harvey, 2008). The processes associated with globalization, and its consequences for urban areas in particular, reinforce the need to re-address the relationship between older people and urban environments. During the 1960s, writers such as Jane Jacobs (1961) and Richard Sennett (1970) argued the case for celebrating the diversity of city life. Later, Richard Rogers and Anne Power (2001) developed a new approach to urban planning, one arguing the case for promoting a sharing of spaces for the collective good, and reversing the drift towards suburbanization. More recently, Katz et al. (2008) have set out an 'agenda for the urban age', one which views expanding conurbations and 'mega-cities' as vehicles for recovering economic growth, promoting environmental sustainability and reducing poverty. Yet the reality is that many groups within the older population feel largely excluded from the ambitious plans produced by cities competing in the global marketplace. Most cities will, in the next decade, have within or around their urban core one in four of their population aged 60 and over. Creating 'age-friendly' cities has, in consequence, become a significant challenge for all aspects of urban design, management and organization. The next section summarizes some of the research findings regarding constraints and opportunities for supporting older people within urban settings.

\section{Ageing in the urban environment}

\section{Pressures and constraints on older people}

Physical environments have a significant impact upon all age groups but especially for those reliant on their immediate locality for support and assistance. Older people may be particularly sensitive to changes in the physical and built environment, given its significance for maintaining a sense of identity (Rowles, 1983), and because of the period likely to be spent within the home - 80 per cent of the time of those aged 70 and above according to one study 
(Horgas et al., 1998). Against this, older people have been largely 'invisible' in discussions around the impact of urban change, an experience shared with disabled people and equivalent groups (Edwards, 2009). On the one side, older people bring great advantages to urban environments - not least because of their knowledge about, and commitment to, their immediate community (Scharf et al., 2002). On the other side, they may experience a variety of pressures reflecting physiological and cognitive vulnerabilities; changing patterns of spatial use; and reliance upon community and neighbourhood relationships for support (Mitchell et al., 2003; Wight et al., 2009).

Urban hazards and risks may affect older people in a number of ways. Traffic congestion and limited provision of public toilets and places to rest, have variously been identified as factors that may reduce the quality of daily life (Phillips et al., 2005; Smith, 2009; Verté et al., 2007). The safety of older pedestrians is a major issue in many cities. Research in New York found that whilst those aged 65 and over comprise 13 per cent of the city's population, they represent 33 per cent of pedestrian fatalities. In 2001 alone, over 1,600 older people were injured or killed in traffic crashes (cited in New York Academy of Medicine, 2008). More recent data for Manhattan, covering the period 2006-08, show pedestrians aged 60 and over account for nearly 47 per cent of pedestrian fatalities despite comprising just 17 per cent of the population (Tri-State Transportation Campaign, 2010). Similarly, a study in Dublin (Romero-Ortuno et al., 2009) showed that pedestrian crossing times at urban intersections represented a major hazard for frail older people, with the standard period allowed to cross the street insufficient for the safety of elderly pedestrians.

Scharf et al. (2002) interviewed 600 people aged 60 and over living in inner-city communities in Liverpool, London and Manchester. Their study found that older people experienced a strong sense of being 'excluded' from many of the organizations and institutions influencing quality of life in their neighbourhoods. Poverty was a major feature of daily life, affecting nearly half of those interviewed. Many respondents could be considered as excluded from involvement in formal social relationships and civic activities within their communities. Moreover, a significant minority of older people were identified as being socially isolated and/or severely lonely. In this context, research in urban areas covering both the UK and the Netherlands found that older people who evaluate their neighbourhood negatively are much more likely to be lonely than those whose neighbourhood quality is judged to be high (Scharf and De Jong Gierveld, 2008).

Urban areas also host a growing number of first generation migrants who experience especially acute problems of poverty and poor housing. The study by Scharf et al. (2002) found that almost eight out of ten older Somali migrants and nearly seven out of ten older people of Pakistani origin found it very difficult to manage on their current incomes. Many of them had to 
cut back on essentials, including food, and had to limit their social activities. Similarly, Becker (2003: 135) highlighted the precariousness of the living conditions of older migrants living in inner-city neighbourhoods in Northern California. This study found that many elders belonging to minority ethnic groups lived in rooms without bathrooms or kitchens, and many others lived in overcrowded apartments. The neighbourhoods in which they lived were areas with a long history of illegal activities such as drug dealing, prostitution and gambling, these presenting particular challenges to creating a sense of home in old age.

High rates of crime in deprived neighbourhoods may also contribute to feelings of insecurity in old age (Smith, 2009). The experience of crime and the perceived risk of criminal victimization may act as psychological barriers which deter older people from leaving their homes, especially after dark (Scharf et al., 2003). Evidence from the Belgian Ageing Studies (De Donder, 2011) demonstrates that neighbourhoods with poor physical environments and limited access to services also increase feelings of insecurity. Conversely, older people who enjoy living in their neighbourhood and have the opportunity to have a say in what their neighbourhood looks like (e.g. through political participation) express fewer problems relating to lack of safety and security. Pain (2000: 365) makes the point here that fear of crime should be seen as inseparable from a range of social and economic problems concerned with housing, employment, environmental planning and social exclusion'.

Older people may be especially vulnerable to environmental changes affecting urban areas. Research in the United States and France has examined problems faced by older people in the midst of environmental crises such as extreme heat waves. Klinenberg (2002) examined the 1995 heat wave in Chicago that during a four-week period had killed around 600 people, with three-quarters aged 65 or over. As well as the immediate factors causing high mortality among older people, Klinenberg (2002: 55) pointed to structural features in the urban environment that reduced the quality of life of elderly residents, these including barriers to physical mobility, such as broken stairs, crumbling sidewalks, and poor lighting; the psychological impact of living amongst signs of disorder; indifferent government agencies who neglect the local infrastructure; and the decrease in trusting and reciprocal relationships in areas with high levels of crime.

Ogg (2005) identified similar issues to the above in his analysis of the 2003 heat wave in France that resulted in an estimated 15,000 deaths, most of whom were older people. Ogg cited several French studies that demonstrated that the highest mortality rates were in urban areas, particularly the Paris and Lyon conurbations. He concluded that, as with the Chicago experience, the French heat wave raised important questions about the quality of life of older people living in densely populated urban areas: 'these environments are often not adapted to the needs of older people and they can be one of the primary 
causes of social exclusion. Spatial and mobility-related aspects of citizenship are increasingly recognised as important dimensions of social inclusion ... and older people in inner cities often face many disadvantages related to access to services' (Ogg, 2005: 35).

The problems identified by Ogg (2005) may be felt most acutely by particular groups of older people, such as those experiencing the moderate or severe cognitive impairments associated with dementia. There are currently around 820,000 people with Alzheimer's and other forms of dementia in the UK, representing 1.3 per cent of the population (Luengo-Fernandez et al., 2010). The majority of people with dementia will live most of their lives at home in their communities, either alone or with relatives or friends (Downs and Bruce, 2006). The needs of this group have, however, been entirely ignored in mainstream urban design, which as Mitchell et al. (2003: 605) observe has focused instead 'on the needs of a much younger demographic group'. Against this, Mitchell and Burton (2006: 29) highlight the importance of a stimulating external environment for people with dementia, with participants in their study: 'preferring vibrant places, such as urban squares surrounded by shops, offices and cafes ... For people fearful that they are losing their ability to always understand what is expected of them in particular environments the more informal, lively, mixed-use settings were seen as more welcoming and safe [in comparison with] formal spaces'.

\section{Opportunities for older people in urban environments}

Despite the constraints, the advantages - both existing and potential - of urban areas for older people may also be highlighted, these including aspects such as the social and cultural resources contained within cities, and the role of cities as centres of innovation; the importance of the attachments and bonds formed within urban neighbourhoods; and the benefits of the urban environment for groups such as first and later generation migrants.

On the first of these, the resources associated with urban communities bring opportunities for enriching many aspects of later life. Museums, libraries, parks and communal spaces may all be used to increase the quality of life in old age. Evidence also suggests that the proximity of amenities and services often creates 'opportunity structures', i.e. 'features of the physical and social environment which may promote health either directly or indirectly through the possibilities they provide for people to live healthy lives' (Macintyre and Ellaway, 2000: 343). Richard et al. (2009), for example, found higher levels of social and cultural participation among older people who had access to facilities such as corner shops, pubs, cafés, libraries and parks. Boudry et al. (2005: 127) make the point that the city can be a catalyst for local initiatives and for innovation', these providing a range of opportunities for older people to become involved in different aspects of community development 
and cultural life. Murray and Crummett (2010) demonstrate this point in their community arts project in inner-city Manchester, where cultural activities were used to challenge marginalization and social exclusion arising from neighbourhood change (see further below).

Another dimension concerns the importance of the various attachments formed within urban neighbourhoods. Here, research suggests that even in areas of intense economic deprivation, older people may identify strongly with their neighbourhood and experience high levels of support. In their study of deprived neighbourhoods in Liverpool, London and Manchester, Scharf et al. (2002) found that three out of four older respondents could identify positive features of their neighbourhood, such as its general 'friendliness' and the presence of 'good neighbours', along with benefiting from the proximity of family and friends. A study of 100 municipalities in Belgium demonstrated that older people living in inner-city Brussels were strongly attached to their locality. Although problems such as 'fear of crime' and 'degradation of the area' were reported more frequently in comparison with other areas, the extent to which older people felt involved with their neighbourhood was significantly higher compared with other communities beyond Brussels (Buffel et al., 2011). A qualitative study on experiences of place among Turkish older migrants living in Brussels also showed the importance attached to neighbours, which was often described by using the Turkish expression 'find your neighbour, choose your house', suggesting that trustful and supportive neighbours are the most important criterion for determining the choice of a home (Buffel et al., 2011). At a more general level, rather than providing limited social support, urban environments may allow people to draw from a wider range of networks as compared with rural areas. Friendship networks, for instance, appear to be especially robust in urban communities and may provide an important support mechanism for those who are single or widowed (Phillipson et al., 2000).

Finally, with respect to groups such as older migrants, urban environments create undoubted pressures, but may bring significant opportunities as well. Access to specialist forms of cultural, social, religious and economic participation and self-organization is an important feature of many cities, but much less common in rural areas. The proximity of members of their own cultural community, often in the same neighbourhood, also offers opportunities for developing social networks and realizing common social bonds (Phillipson et al., 2002). A study in an urban area in Northern California emphasized the problematic living conditions in which ethnic elders live, yet these urban environments also appeared to be sources of social connections and long-term, intimate friendships (Becker, 2003). According to Becker, much more attention should be given to the range and complexity of the social connections of older migrants in urban areas. Research in Germany has shown that older Turkish migrants tend to be well integrated into social 
networks, as they often live in intergenerational households and maintain strong, supportive ties with their family and other community members. According to this study, older Turkish migrants are in fact less affected by social isolation than their German counterparts (Naegele, 2008).

\section{Options for critical social policy}

The need to build urban communities able to increase opportunities for maintaining and enhancing the quality of life as people age is assuming greater urgency within social policy. On the one hand, promoting the wellbeing and contributions of older urban residents is considered to be a key factor in maintaining thriving cities (WHO, 2007a). On the other hand, supporting the inclusion and participation of older city-dwellers must be viewed as a crucial part of the agenda for sustainable urban development. However, implementing this agenda is likely to require radical interventions. Three issues require particular attention:

- First, recognizing the diversity of cities and the implications for the 'age-friendly' approach.

- Second, developing new forms of 'urban citizenship' which recognize and support changing needs across the life course.

- Third, creating opportunities to involve ageing populations more effectively in the planning and regeneration of neighbourhoods.

The first question is whether the use of a universal checklist of action items as a starting point for creating age-friendly communities is the most adequate method to deal with the 'diversity' of cities and the heterogeneity of their populations (young as well as old). In addition, whilst the trend towards urban living is global, the pattern of urban growth itself shows considerable variation: shrinking urban populations in many high-income countries but accelerating urbanization in some low-income countries (UN-Habitat, 2008). Attempts to make a city 'age-friendly' will also vary greatly according to population size and density. For example, the approach might differ in Europe where small cities with fewer than 500,000 residents are the norm, as compared with the USA where large urban agglomerations (with populations of between two and five million) are much more common. Other variations might be required in the context of the rise of 'mega-cities' and 'hyper-cities', the latter with populations of 20 million or more (UN-Habitat, 2010). At the same time, the methods for creating 'age-friendly' communities will need radical adjustment in the context of the 'slum cities' prevalent for example in sub-Saharan Africa and Southern Asia. Population growth in these continents has to a large extent taken place through the rise of slums, many of these 
clustered on the periphery of capital cities (Davis, 2006). The variety of types of urban development underlines the need for new models of intervention that can respond to the highly unequal contexts experienced by urban ageing populations across the world.

A second issue concerns the need to link the debate about developing age-friendly cities to ideas about 'urban citizenship' and the right to make full use of the city. The concept of 'the right to the city' is closely associated with the work of Lefebvre (1991) and has become a keyword for analysing the struggles over the shape of the city and access to public space - or, in Harvey's terms (2009: 315), the right to 'make and remake our cities and ourselves' under circumstances in which private capital is dominating the urban process. Commenting on Lefebvre's work, Purcell (2003: 577-578) argues that 'the right to the city' implies two main rights for its inhabitants. The first is to appropriate urban space; the right to 'full and complete usage' of the city. The second concerns the right to participate centrally in decisionmaking surrounding the production of urban space.

These issues may be of particular importance for older people who become reliant upon their immediate environment for achieving a fulfilling existence in old age. However, the so-called 'paradox of neighbourhood participation' (Buffel et al., 2012) applies especially well to older people, i.e. they tend to spend a lot of time in their neighbourhood (being part of the city), but are often among the last to be engaged when it comes to decision-making processes within their neighbourhood (taking part in the city). While cities are increasingly viewed as key drivers of a nation's economic and cultural success, their reconstruction is often to the detriment of those outside the labour market, especially those with low socio-economic status. Achieving recognition of the needs of different generations within cities, and exploiting the potential of the city for groups of whatever age, will be central to the process of making cities more age-friendly.

Developing new forms of urban citizenship will be especially important given the growth of migrant populations within urban areas. Global cities host growing numbers of residents who have reached, or are on the threshold of old age, and whose current life conditions have been influenced by trans-national migration in various forms. Older (especially first generation) migrant populations have diverse social and economic characteristics with marked inequalities between different ethnic groups (Nazroo, 2006). However, Warnes et al. (2004: 307) make the point that: 'all to a greater or lesser extent are disadvantaged through an interaction between social policies and their "otherness" by living in a foreign country'. Research in various countries highlights the precariousness of the living conditions of older migrants living in urban areas, especially in relation to personal safety and access to good quality housing (Becker, 2003; Naegele, 2008; Scharf et al., 2002). Yet, older migrants also strive to create a 'sense of home', notably through establishing 
new communal spaces and amenities (Buffel and Phillipson, 2011). The key issue is the extent to which age-friendly policies can build upon the varied resources and life histories which older migrants bring to urban living. In this context, it will be especially important to recognize the emergence of new forms of urban citizenship linked to the rise of the global city, with the need for policies which recognize the variety of circumstances and resources characteristic of older migrants (Torres, 2006).

Third, and following the above, making cities more 'age-friendly' will require radical interventions for involving older people and those approaching old age as key actors in setting the agenda for future urban development. Urban regeneration policies can, for example, benefit from the skills and experience of older people and the attachment and involvement they bring to their communities. A study in England by Riseborough and Sribjilanin (2000), however, demonstrates that elderly people tend to be 'invisible' in the implementation of urban regeneration. Simpson's research (2010: 316) reinforces this point and confirms that despite increased recognition of older people's influence on their communities, involvement in urban regeneration processes remains 'relatively limited, unnecessarily restricted, and considerably diluted' at the strategic level.

Policy strategies for making cities more age-friendly will therefore require a clear assessment of the (structural) barriers and vehicles to engaging older people in community redevelopment. At the same time, there is also a need to develop strategies targeted at different groups within the older population, with awareness, for example, of contrasting issues faced by different ethnic groups, people with particular physical or mental health needs, and those living in areas with poor housing alongside high population turnover (Phillipson et al., 2000).

The diversity of groups within the older population is likely to mean that the process of developing age-friendly communities will involve reconciling conflicting interests and concerns. In consequence, rather than focusing on prescribed 'outcomes' for achieving 'age-friendliness', there is a need for developing new models of community development which will work with the range of concerns within and between different age groups. Such an approach faces particular challenges in terms of involving those older people experiencing intense forms of exclusion - such as those associated with extreme loneliness and chronic poverty (Scharf et al., 2002). A key role for social policy and community development will be to enhance the 'agency' of these particular groups, expanding opportunities to assist their engagement with the changing conditions within neighbourhoods.

Social policies can promote older people's participation in community redevelopment in a number of ways, notably by ensuring greater use of the different resources which accompany urban living (see further above). This may involve a range of different interventions, such as developing access to 
high quality public space and supporting neighbourhood-based organizations. 'Mainstreaming' ageing issues within urban development represents a major challenge for social and public policy, as well as for community organizations and older people themselves. Another will be to create opportunities for older people to have a voice in political decision-making, through advisory boards or action groups which engage in different aspects of urban development. However, it is important to note that strategies for promoting citizenship participation cannot treat older people as a homogeneous group with shared preferences and interests (Phillipson and Scharf, 2004). While some older people are no longer able or prefer not to invest in the community, others express a strong desire to become or stay connected to their locality in a meaningful way. Moreover, there is a great diversity in the ways in which older citizens wish to become involved in shaping community development strategies, in terms of the roles they play, the projects they engage in and their level of commitment. Therefore, future developments would benefit from evaluations of specific models of community development which reflect the range of citizenship practices among older adults. The next section will examine two projects from different countries that have the potential to offer a way forward in understanding the dynamics underlying the processes of community capacity-building.

\section{Involving older people in developing age-friendly urban environments}

Involving older people in the development and maintenance of 'age-friendly' environments represents a crucial goal for social policy. Achieving this, however, will require a radical shift from producing urban environments for people to developing neighbourhoods with and by older people. Two examples of projects which recognize the importance of involving older people in their environment are used here to highlight the potential value of such an approach: the 'Community Action in Later Life - Manchester Engagement' (CALL-ME) project in England and the 'Belgian Ageing Studies' (BAS) project. Both seek to promote strong links between research, policy and older people.

The CALL-ME study (Murray and Crummett, 2010; Scharf et al., 2009) is an ongoing project based in four disadvantaged neighbourhoods in Manchester. Representing a collaboration between a research team, Manchester City Council, ${ }^{2}$ an array of local stakeholders, and older people, the aims of the project are: first, to identify the issues older residents themselves find important regarding social engagement and independence; second, to assess the impact of community initiatives on active ageing; third, to identify the processes involved in promoting active ageing through such community 
initiatives; and fourth, to develop policy recommendations for promoting active ageing in disadvantaged neighbourhoods. Adopting a participatory action research design, the project has facilitated community involvement in the design and implementation of a broad range of community initiatives spanning the arts, environmental improvement, the use of new technologies, and health-promoting activities. In each neighbourhood, diverse groups of older people are involved in setting the agenda, developing action plans, and monitoring the process.

One of the initiatives, for example, involves transforming a neglected piece of land located at a busy crossroad in the Moss Side community into a 'community peace garden'. This initiative has been led by a group of older residents, but also involves close co-operation with local agencies, and with young people from the local area in creating a sustainable garden at the heart of this socially diverse community. Initial research findings suggest that the involvement of, and co-operation between, older people and different stakeholders, including both formal and third sector agencies, has been an important factor in terms of establishing a sustainable community initiative (Middling et al., 2011). A second initiative in a different neighbourhood of Manchester engaged older people in a range of arts-based activities designed to explore participants' connections with both their material and psychosocial worlds. The project highlighted the value not only of providing socially isolated older people with opportunities for social interaction, but also of enabling participants to work together in a way that allowed them to challenge the negative representations of their community (Murray and Crummett, 2010: 784).

The project of the Belgian Ageing Studies (Verté et al., 2007) refers to a research programme which monitors local challenges and opportunities, as well as issues of quality of life, among home-dwelling older people in order to provide tools for evidenced-based 'age-friendly' policies at local level. The project is a result of a close collaboration between a research team, the regional government and councils of all participating municipalities, senior advisory boards, local social services, and other stakeholders. Through a participatory method, older people themselves are actively involved as actors in all stages of the project. They play a crucial role in the planning, the design, and the realization of the research project, as well as in the development of local policy plans on the basis of the findings of the research. In each of the 120 participating municipalities, a number of older volunteers were recruited who facilitated and monitored the research process, for instance through delivering questionnaires to respondents personally and collecting them when completed. Research is viewed as a tool for creating community networks on the one hand and empowerment of older people on the other. The creation of a community network between local authorities, members of local senior organizations, third sector agencies and other community 
stakeholders is crucial for developing broadly based support around the theme of age-friendly environments. Empowerment is promoted through a cycle of research, participation, education, community action and policy-making.

One of the initiatives that arose from this project, for example, was in the city of Bruges, where the results of the BAS study in 2004 indicated lower neighbourhood involvement and lower civic engagement among older people as compared with other cities. These findings were discussed in a number of forums organized by the stakeholders' network and the older volunteers who were involved in the study. As a result, local action plans were developed focusing on initiatives to promote community cohesion. In several localities, community work was developed aimed at involving local residents to identify social needs, the ways of meeting these, and the available resources. Alongside local associations, community centres and other stakeholders, older volunteers played an important role in planning, taking action and creating opportunities for social change in their neighbourhood. A number of community-building initiatives and strategies were developed, including the organization of neighbourhood festivals, the promotion of accessibility of meeting places for older citizens, and the organization of introductory internet courses in community centres which resulted in the creation of 'neighbourhood websites'. The stakeholders' network as well as older people who are active in advisory boards played a crucial role in influencing social policy here, which, as a result, invested in these local community initiatives by providing funding. In 2010, a follow-up BAS has been conducted in Bruges to examine trends in the municipality. The results of this study indicate a significant increase in neighbourhood involvement as well as in community engagement among older residents.

\section{Conclusion}

Involving older people in the management and regeneration of cities has become a major concern given demographic trends and the complexity of changes associated with urbanization. Yet the evidence suggests that older people remain among the most excluded of those living in urban communities (UN-Habitat, 2010). Moreover, as argued in this paper, despite the growth of the 'age-friendly approach', they rarely feature in policies aimed at regenerating localities or broader efforts aimed at promoting sustainable urban development. In this context, elderly people illustrate many of the tensions and conflicts running through urban change. On the one side has been the impact of land privatization with, in the case of the UK, multinational property companies now controlling 'large chunks' of its cities (Minton, 2009: 19). The impact of private developers on urban planning has been spelt out by Davis (2010: 41) as follows: 'Where urban forms are dictated by 
speculators and developers, bypassing democratic controls over planning and resources, the predictable social outcomes are extreme spatial segregation by income or ethnicity, as well as unsafe environments for children, the elderly and those with special needs'. And Harvey (2008: 31) refers to the way in which the quality of urban and city life has become: 'a commodity ... in a world where consumerism, tourism, cultural and knowledge-based industries have become major aspects of the urban political economy'.

Against the above are pressures to de-commodify urban life, reflecting demands from ageing populations, the diverse cultures of migrant groups, and the needs of younger people facing long-term unemployment and social marginalization. For these groups, debates about the 'right to the city' have taken on a renewed sense of urgency. Minton (2009: 179) makes the point that over the past decade or so we appear to have made the city: 'a far more fearful place ... [with a drift] towards a more authoritarian and less democratic city'. Such developments raise important issues for the different populations living in cities, and not least the growing numbers of older people. The future of old age will, to a large degree, be determined by the extent to which living in cities is made to feel a natural part of growing old. Of course, cities can be disabling and threatening environments at any age. The difference is that at 75 or 85 years of age, people may feel an even greater sense, when compared with other groups, of being disadvantaged by the pace of urban change. Developing new policies and approaches to involving older people in the social and economic life of cities will be a crucial task for urban development in the years ahead.

\section{Notes}

1. For a history of ideas about utopian or 'ideal cities' see Eaton (2001).

2. For a review of Manchester City Council's plan for supporting older people see Manchester City Council (2010).

\section{References}

Atlanta Regional Commission (2009) Lifelong Communities: A Framework for Planning [http://www.atlantaregional.com/aging-resources/lifelongcommunities/lifelongcommunities], accessed 20 May 2010.

Austin CD, Descamp E, Flux D, McClelland R, and Sieppert J (2005) 'Community Development with Older Adults in their Neighbourhoods: The Elder Friendly Communities Program', Families in Society: The Journal of Contemporary Social Services 86(3): 401-409.

Becker G (2003) 'Meanings of Place and Displacement in Three Groups of Older Immigrants', Journal of Aging Studies 17: 129-149.

Bernard M, Bartlam B, Biggs S, and Sim J (2004) New Lifestyles in Old Age: Health, Identity and Well-being in Berrybill Retirement Village. Bristol: Policy Press. 
Biggs S, Bernard M, Nettleton H, and Kingston P (2000) 'Lifestyles of Belief: Narrative and Culture in a Retirement Community', Ageing E Society 20(6): 649-672.

Boudry L, Cabus P, Corijn E, De Rynck F, Kesteloot C, and Loeckx A (2005) The Century of the City: City Republics and Grid Cities. Brussels: Vlaamse Gemeenschap.

Buffel T and Phillipson C (2011) 'Experiences of Place among Older Migrants Living in Inner-City Neighbourhoods in Belgium and England', Diversité Urbaine 11(1): 13-38.

Buffel T, De Donder L, Dury S, De Witte N, and Verté D (2011) 'Het Potentieel van de Buurt. Kansen en Beperkingen van de Stad voor het Proces van Ouder Worden', pp. 444-455 in F Cockx, H De Blende, G Gehre, G Van den Eeckhaut, and G Verschelden (eds) Handboek Sociaal-Cultureel Werken met Volwassenen. Wissels. Gent: Academia Press.

Buffel T, Verté D, De Donder L, De Witte N, Dury S, Vanwing T, and Bolsenbroek A (2012) 'Theorising the Relationship between Older People and their Immediate Social Living Environment', International Journal of Lifelong Education 30(1): 13-32.

Burdett R and Sudjic D (eds) (2008) The Endless City. London: Phaidon.

Davis M (2006) Planet of Slums. London: Verso.

Davis M (2010) 'Who Will Build the Ark?', New Left Review 61 (January-February): 29-48.

De Donder L (2011) Feelings of Unsafety in Later Life. Brussel: VUBpress.

Department for Communities and Local Government (2008) Lifetime Homes, Lifetime Neighbourboods: A National Strategy for Housing in an Ageing Society. London: Department of Health, Department for Work and Pensions.

Downs M and Bruce E (2006) 'Is There a Better Future for People with Dementia and their Families?', pp. 147-153 in J Vincent, C Phillipson, and M Downs (eds) The Futures of Old Age. London: SAGE.

Eaton R (2001) Ideal Cities: Utopianism and the (Un) Built Environment. London: Thames and Hudson.

Edwards C (2009) 'Regeneration Works: Disabled People and Area-based Renewal', Critical Social Policy 29(4): 613-633.

European Union (1999) Active Ageing: Pivot of Policies for Older People in the New Millennium [europa.eu.int/comm./dgs/employment-social/speeches/91116ad. doc], accessed 19 August 2009.

Evans S (2009) Community and Ageing: Maintaining Quality of Life in Housing with Care Settings. Bristol: Policy Press.

Harvey D (2008) 'The Capitalist City', New Left Review 53 (September-October): $23-42$.

Harvey D (2009) Social Justice and the City, revised edn. Athens, GA: University of Georgia Press.

Horgas AL, Wilms HU, and Baltes MM (1998) 'Daily Life in Very Old Age: Everyday Activities as Expressions of Daily Life', Gerontologist 38(5): 556-568. 
Jacobs J (1961) The Death and Life of Great American Cities. New York: Random House.

Katz B, Altman A, and Wagner J (2008) 'An Agenda for the Urban Age', pp. 474-481 in R Burdett and D Sudjic (eds) The Endless City. London: Phaidon.

Klinenberg E (2002) Heatwave: A Social Autopsy of Disaster in Chicago. Chicago: University of Chicago Press.

Lefebvre H (1991) The Production of Space. Oxford: Blackwell.

Luengo-Fernandez R, Leal J, and Gray A (2010) Dementia 2010. London: Alzheimer's Research Trust.

Lui CW, Everingham JA, Warburton J, Cuthill M, and Bartlett H (2009) 'What Makes a Community Age-Friendly: A Review of International Literature', Australasian Journal on Ageing 28(3): 116-121.

Macintyre S and Ellaway A (2000) 'Ecological Approaches: Rediscovering the Role of the Physical and Social Environment', pp. 332-348 in L Berkman and I Kawachi (eds) Social Epidemiology. Oxford: Oxford University Press.

Manchester City Council (2010) A Great Place to Grow Older 2010-2020. Manchester: Manchester City Council.

Middling S, Bailey J, Maslin-Prothero S, and Scharf T (2011) 'Gardening and the Social Engagement of Older People', Working with Older People 15(3): 112-122.

Minton A (2009) Ground Control: Fear and Happiness in the Twenty-First-Century City. London: Penguin Books.

Mitchell L and Burton E (2006) 'Neighbourhoods for Life: Designing DementiaFriendly Outdoor Environments', Quality in Ageing and Older Adults 7(1): 26-33.

Mitchell L, Burton E, Raman S, Blackman T, Jenks M, and Williams K (2003) 'Making the Outside World Dementia-Friendly: Design Issues and Considerations', Environment and Planning B: Planning and Design 30(4): 605-632.

Murray M and Crummett A (2010) “I Don't Think They Knew We Could Do These Sorts of Things": Social Representations of Community and Participation in Community Arts by Older People', Journal of Health Psychology 15(5): 777-785.

Naegele G (2008) 'Age and Migration in Germany: An Overview with a Special Consideration of the Turkish Population', Gerobilim Journal of Social E Psychological Gerontology [http://gerobilim.com/index.php?id=43], accessed 4 June 2010.

Nazroo J (2006) 'Ethnicity and Old Age', pp. 62-72 in J Vincent, C Phillipson, and M Downs (eds) The Futures of Old Age. London: SAGE.

New York Academy of Medicine (2008) Towards an Age-Friendly City: A Findings Report. New York: New York Academy of Medicine.

Ogg J (2005) Heat Wave. London: The Young Foundation.

Pain R (2000) 'Place, Social Relations and the Fear of Crime: A Review', Progress in Human Geography 24(3): 365-387.

Phillips DR, Siu O, Yeh AG, and Cheng KHC (2005) 'Ageing and the Urban Environment', pp. 147-163 in GJ Andrews and DR Phillips (eds) Ageing and Place: Perspectives, Policy, Practice. London: Routledge. 
Phillipson C and Scharf T (2004) The Impact of Government Policy on Social Exclusion among Older People. London: Office of the Deputy Prime Minister, Social Exclusion Unit.

Phillipson C, Bernard M, Phillips J, and Ogg J (2000) The Family and Community Life of Older People. London: Routledge.

Phillipson C, Ahmed N, and Latimer J (2002) Women in Transition: A Study of Experiences of Bangladeshi Women Living in Tower Hamlets. Bristol: Policy Press.

Purcell M (2003) 'Citizenship and the Right to the Global City: Reimagining the Capitalist World Order', International Journal of Urban and Regional Research 27(3): 564-590.

Richard L, Gauvin L, Gosselin C, and Laforest S (2009) 'Staying Connected: Neighbourhood Correlates of Social Participation among Older Adults Living in an Urban Environment in Montréal, Québec', Health Promotion International 24(1): 46-57.

Riseborough M and Sribjilanin A (2000) Overlooked and Excluded? Older People and Regeneration: A Review of Policy and Practice. London: Age Concern England.

Rogers R and Power A (2001) Cities for a Small Country. London: Faber.

Romero-Ortuno R, Cogan L, Cunningham CU, and Kenny RA (2009) 'Do Older Pedestrians Have Enough Time to Cross Roads in Dublin? A Critique of the Traffic Management Guidelines Based on Clinical Research Findings', Age and Ageing 39(1): 80-86.

Rowles GD (1983) 'Place and Personal Identity in Old Age: Observations from Appalachia', Journal of Environmental Psychology 3(3): 299-313.

Satterthwaite D (ed.) (1999) The Earthscan Reader on Sustainable Cities. London: Earthscan.

Scharf T and De Jong Gierveld J (2008), 'Loneliness in Urban Neighbourhoods: An Anglo-Dutch Comparison', European Journal of Ageing 5: 103-115.

Scharf T, Phillipson C, Smith A, and Kingston P (2002) Growing Older in Socially Deprived Areas: Social Exclusion in Later Life. London: Help the Aged.

Scharf T, Phillipson C, and Smith A (2003) 'Older People's Perceptions of the Neighbourhood: Evidence from Socially Deprived Urban Areas', Sociological Research Online [http://www.socresonline.org.uk/8/4/scharf.html], accessed 18 May 2010. Scharf T, Ziegler F, Murray S, Maslin-Prothero S, Beech R, Bailey J, Middling S, and Crummett A (2009) 'Towards More Inclusive Urban Communities for Older People? Initial Findings from the CALL-ME Project', Poster presented at the World Congress of Gerontology and Geriatrics, 7 July, Paris.

Sennett R (1970) The Uses of Disorder: Personal Identity and City Life. New York and London: W. W. Norton.

Simpson C (2010) 'Older People and Engagement in Neighbourhood Renewal: A Qualitative Study of Stoke-on-Trent', Unpublished PhD Thesis, Keele University.

Smith A (2009) Ageing in Urban Neighbourboods. Bristol: Policy Press. 
Torres S (2006) 'Culture, Migration, Inequality, and "Periphery" in a Globalized World: Challenges for Ethno- and Anthropogerontology', pp. 231-244 in J Baars, D Dannefer, C Phillipson, and A Walker (eds) Aging, Globalization and Inequality: The New Critical Gerontology. New York: Baywood Press.

Tri-State Transportation Campaign (2010) Older Pedestrians at Risk and How States Can Make it Safer and Easier for Older Residents to Walk. New York: Tri-State Transportation Campaign.

UN-HABITAT (2008) State of the World's Cities 2008/2009. London: Earthscan. UN-HABITAT (2010) State of the World's Cities 2010/2011. London: Earthscan.

Verté D, De Witte N, and De Donder L (2007) Schaakmat of aan Zet? Monitor voor Lokaal Ouderenbeleid in Vlaanderen. Brugge: Vanden Broele.

Warnes AM, Friedrich K, Kellaher L, and Torres S (2004) 'The Diversity and Welfare of Older Migrants in Europe', Ageing E Society 24: 307-326.

Wight RG, Cummings JR, Karlamangla AS, and Aneshensel CS (2009) 'Urban Context and Change in Depressive Symptoms in Later Life', Journal of Gerontology: Psychological Sciences 64B(2): 247-251.

World Health Organization (2002) Active Aging: A Policy Framework. Geneva: WHO. World Health Organization (2007a) Global Age-Friendly Cities: A Guide. Geneva: WHO Press.

World Health Organization (2007b) Checklist of Essential Features of Age-Friendly Cities. Geneva: WHO Press.

\section{Author Biographies}

Tine Buffel obtained her Master's degree in Adult Educational Sciences at the Vrije Universiteit Brussel (VUB) in 2006 and currently works as a research assistant in the department of Adult Educational Sciences at the VUB, with a scholarship from the Fund for Scientific Research Flanders. Her PhD focuses on older people's relationship with the local environment, using critical and environmental perspectives on ageing. Recent publications: Buffel, T., Verté, D., De Donder, L., De Witte, N., Dury, S., Vanwing, T. and Bolsenbroek, A. (2012) 'Theorising the relationship between older people and their immediate social living environment', International Journal of Lifelong Education 30(1): 13-32; Buffel, T., Verté, D., Dury, S. and De Witte, N. (2009) 'Conceptualizing the neighbourhood as a dynamic social space: Recognizing older people as actors in place-making', at ESA 2009, 'European Society or European Societies?', 4 September, Lissabon: The European Sociological Association.

Chris Phillipson, PhD, is Professor of Applied Social Studies and Social Gerontology, at the University of Keele, UK. He was founding Director of the Centre for Social Gerontology at Keele. His research interests have focused on family and community life in old age, problems of social exclusion, and issues relating to urbanization and migration. Recent publications: Baars, J., Dannefer, D., Phillipson, C. and Walker, A. (eds) (2006) Aging, Globalization and Inequality: The New Critical Gerontology (Baywood Press); Dannefer, D. and Phillipson, C. (eds) (2010) Handbook of Social Gerontology (SAGE). 
Thomas Scharf is Professor of Social Gerontology and, since 2010, Director of the Irish Centre for Social Gerontology at NUI Galway, Ireland. He was previously Professor of Social Gerontology and Director of the Centre for Social Gerontology at Keele University, UK. His research encompasses the fields of social gerontology, social policy and political science, with a particular focus on aspects of disadvantage faced by older people. Recent publications: Scharf, T. (2010) 'Social policies for ageing societies: Perspectives from Europe', in C. Phillipson and D. Dannefer (eds) Handbook of Social Gerontology (SAGE); Scharf, T. (2009) 'Too tight to mention: Unequal income in older age', in P. Cann and M. Dean (eds) Unequal Ageing: The Untold Story of Exclusion in Old Age (Policy Press). 